\title{
EFFECTIVENESS OF COGNITIVE-BEHAVIORAL PROGRAM ON REDUCING MOTHERS' BURDEN OF CARE OF THEIR CHILDREN WITH AUTISM DISORDER
}

\author{
Zeinab Hassan Hassan Osman ${ }^{1 *}$, Enaam Abdellatif Farrag ${ }^{1}$, Azza El-Sayed Ali Hegazy² \\ ${ }^{1}$ Psychiatric Mental Health Nursing, Faculty of Nursing, El-Fayoum University, Egypt \\ ${ }^{2}$ Pediatric Nursing, Faculty of Nursing, El-Fayoum University, Egypt \\ *Corresponding Author'sEmail:zz_osman@yahoo.com
}

\begin{abstract}
Background: Children with autism have trouble communicating, they also have trouble understanding what other people think and feel. This makes it very hard for them to express themselves either with words or through gestures, facial expressions and touch. Aim: The aim of this study was to assess, plan, implement and evaluate the effect of cognitive-behavioral program on reducing mothers' burden of care of their children with Autistic disorders. Methodology: A quasi experimental research design with pre-post assessment was used. The study subjects included 45 mothers with Autistic children attending childs' Clinics of El-A bbassia Governmental Hospital and childrens' Centers at El-Fayoum city as Sondos Academy within a period of 6 months with their children. Results: This study concluded that the prevalence of autism was much higher among females in this Egyptian sample. There was statistically significant differences pre and post program between the level of mothers' knowledge, skills and behavior. There was a highly statistically significant difference between pre and post program as regards the total scores of mothers' coping pattern to decrease their psychological and social stresses, which improved in post program. There were statistically significant positive correlations between parents' burden and daily living activities among the children studied. Recommendation: The stydy will help to develop educational programs to increase mothers' knowledge and awareness about the nature and management of autism all over the country.
\end{abstract}

Keywords: Autistic Disorder, Daily living activities, Mothers'burden, Cognitive-Behavioral Domain

\section{INTRODUCTION}

Autistic spectrum disorders (ASD) are a set of Neuro developmental disorders that cover the lifespan. It is a complex developmental disability that typically appears during the first three years of life (Liss et al., 2011). Autistic disorder includes three areas of abnormality with impaired social interactions (failure to develop peer relationship, no eye contact or other nonverbal interactive behaviors, no seeking to share enjoyment with others, or lack of social response), impaired communication (delay or lack of language, stereotyped language, repetition of words said by others, or lack of imaginative play) and stereotyped behavior (inflexibility, preoccupation with odd interests, strict adherence to nonfunctional routines, or repetitive mannerisms such as hand flapping or head banging) (Matson \& Rivet, 2016).

The prevalence of autism spectrum disorder among children is 1 in 150 children worldwide. Autism is four times prevalent in boys than girls (Center for disease control \& prevention, 2014). While Hafiz, (2007) found in his study that one child in every 870 Egyptian child has Autism.

The exact cause of autism is unknown.There are many environmental factors and biological predispositions. The environmental concerns as exposure to heavy metals such as lead and mercury. Some of the disorders associated with increased rates of autism include the rare genetic conditions involving a variant of the MET gene. The MET gene is involved in brain development, or it may be the result of a neurological 
disorder that affects the functioning of the brain (Carmichael, 2016).

During early childhood, frequent routine wellness checks are scheduled; these visits allow the physicians and nurses to regularly evaluate a child's physical, emotional and communication development. The nurse must be familiar with normal developmental milestones and be able to recognize when there is a deviation from the normal range of development. The nurse must be able to recognize the needs for and understand the various forms of diagnostic and testing procedures for the child suspected to have autism (Carmichael, 2016).

The overall impact of having a child with ASD on a family can create severe psychological stress. From the initial diagnosis to the ongoing, day-to day demand of caretaker responsibilities. But for some families, caretaking can be overwhelming. Parents of children diagnosed with ASD struggle with many challenges associated with the disorder resulting in more stress (Biligin \& Kucuk, 2010). The stressors involve problems associated with the characteristics of the disorder, which include social skills, communication and in many cases, behavioral difficulties. Parents; mothers in particular are more vulnerable to psychological and emotional problems due to the isolation and day to day demanding tasks of caring for a child with ASD (Sawyer et al., 2012).

The life long adoption programs focus on those skills that are needed for the successful day to day functioning of autistic children in their environment. Areas of daily living skills are related to self-help at home or school, community and leisure skills. Self- help skills are those skills enabling individuals to take care of their own bodies. There is a large deficit area for individuals diagnosed with autistic disorder. If the individual learns self-help skills, then he/she will become more independent, and therapy will allow caregivers to focus on other areas (Wood, 2012).

Daily living skills, defined as age-appropriate selfcare activates needed to function at home and community, which includes behaviors such as washing, dressing, following safety rules and completing household chores. Daily living skills should be an area of relative strength, and commensurate with a child's mental age (Gilham et al., 2011). Yet, deficits in daily living skills have been found consistently in children with ASD. Moreover, the development of daily living skills in young children with ASD has not been fully examined, despite evidence that daily living skills are delayed in those children (Perry et al., 2009).

The most significant role of the nurse in Autism recognition and diagnosis is education. The nurse must be able to provide assistance with personalized education plans and referrals to support services with specialty medical aid. Being readily available and knowledgeable as an educator and promoter is often the most important role that the nurse can play in the care and treatment of a child with an autistic disorder (Howlin, 2017; Mandellet et al., 2006). The nurses' first strategy for caring of those children is the recognition of signs and symptoms of autism. Some of the cardinal signs include difficulties with socialization, impairment of verbal and nonverbal communications, repetitive and restricted behavioral patterns (Howlin, 2017).

The primary goals of treatment are to minimize the core features and associated deficits, maximize functional independence and quality of life and alleviate family distress. Facilitating development and learning, promoting socialization, reducing maladaptive behaviors, and educating and supporting families can help in achieving these goals (Howlin, 2017; Green \& Carter, 2014). Therefore, implementing an educational program for those families or mothers is helpful in the acquisition of knowledge and practices regarding the disease and relief their stresses. Also, it is an essential step to assist mothers and their children to cope effectively with the disease and its management and reach adulthood safely. They must be permissible to live a normal life as far as possible and the burden of care must be decreased.

\section{Aim of the Study}

This study aimed to assess, plan, implement and evaluate the effect of cognitive-behavioral education program on reducing mothers' burden of care towards their children with Autistic disorder.

\section{Research Hypothesis}

Mothers of children with Autism after reciving this training program, will gain high scores of knowledge and practices immediately post program more than before the program implementation.

\section{Significance of the study}

Autistic disorder is a lifelong disability and most 
children affected with this condition remains unable to live independently and require family and community support or institutionalizations. So, the goals of treatment for those children are to reduce disruptive behaviors and promote learning, particularly language acquisition, communication and self-help skills. These goals are best achieved after a comprehensive assessment of strengths and needs. Moreover based on this assessment a structured and individualized intervention is recommended (Filipek et al., 2014).

So this study will be conducted to identify the needs and problems of mothers and their children. The sudy will also review new insights, key therapies and specific guidelines for more effective treatment strategies so as to educate mothers. This way they can reduce the burden of care. Mothers were taken as a sample for this study because the child with Autism needs more care than a hospital admission. Sufficient support for mothers may prevent or ameliorate these problems and they might indirectly achieve better outcomes. Therefore, implementing an educational program for mothers will be helpful in the acquisition of knowledge and practices regarding the disease and relief the mothers' stress and burden of children' care.

\section{RESEARCH METHODOLOGY}

The subjects and methods of this study were portrayed under four main designs as follows:

I. Technical design.

II. Operational design.

III. Administrative design.

IV. Statistical design.

\section{Technical Design}

\section{The technical design included the following:}

\section{Research design}

A quasi experimental research design with pre-post assessment was used.

\section{Settings}

This study was conducted at El-Tarbya El-Fekrya Schools and Development Referral Centers at ElFayoum City as Sondos Acadamy, Ibny Center and Together Center and Child Clinic of EL-Abbassia Governmental Hospital. These clinics provide services for children suffering from psychiatric disorders. This care includes interventions in reducing mothers' burden of care of their children with Autism disease; the researchers interviewed the mothers of autistic child 2 days per week for 6 months.

\section{Sample}

This study was carried out on a convenience sample (45 mothers and their children) who have been diagnosed with autism at out-patient clinics of the previously mentioned settings:

\section{Inclusion criteria of sample selection}

- Mothers of autistic child, regardless their age and education level.

- Children, with Autism, regardless their age and sex.

- Voluntary participation

\section{Exclusion criteria}

Children with mental retardation and neurological disorders.

\section{Tools of data collections}

Mothers' assessment sheet: Was designed, validated and utilized by the researchers to collect the necessary data. It consisted of 4 parts:

\section{Personal characteristics and clinical data sheet for} children and their mothers:

This tool was developed by the researchers, it included (15) item for socio-demographic data divided into two parts which included data about autistic children and their mothers.

Part 1: For mothers: It included age, level of education, occupation, marital status, income and number of family members and place of residence.

Part 2: For child It included age, gender, rank of the child, number of his $\backslash$ her sibling, degree and onset of the disorder as well as the family history of autism.

\section{Knowledge of mothers scale regarding Autism:}

This scale was developed by the researchers, it contained 10 items designed to assess knowledge about autism. Mothers were asked to circle one of three responses.

\section{Behavior of mothers scale regarding Autism:}

This scale developed by the researchers consisted 
of 11 items designed to assess behavior about autism. Response options (correct or incorrect and I don't know).

\section{Coping pattern to decrease burden:}

This scale was developed by the researchers and included five items designed to assess skills to decrease the burden. Mothers were asked if they know or do not know).

\section{Perception of stress:}

This scale developed by Levenstein (1993) composed of 30 items designed to assess pressure on mothers with autistic children. Participants were asked to choose never, almost, sometimes, a lot of and always.

Response options are (never $=0$, almost $=1$, sometimes $=2$, a lot of $=3$ and always $=4$ ). All items are answered with a total score 30 .

\section{Structured Teaching Program description:}

The main goals were aimed to determine the effect of cognitive-behavioral program on mothers' burden of care for children with Autitic disorder.

\section{Specific objectives:}

1. To teach child's mother about autism

2. To enhance child's daily life activities

3. To decrease mothers' burden of their child care.

The study program was designed to be 15 sessions implemented in four phases, where the first two sessions were for assessment, program sessions were 12 sessions and final session was for evaluation.

\section{Procedure:}

-A review of the past and current Arabic and English related literature covering various aspects of the problem was done, using available books, articles, periodical, magazines and internet to get acquainted with the research problem and construct the program.

-Content validity of the program was tested by five experts in psychiatry, pediatric nursing and medicine field.

-Modifications of the program were done in response to the panel's judgment on the appropriateness of the program content.
-Training the investigator: the investigator obtained a certificate indicating her attendance and participation about developing skills of autistic children.

-An official permission was obtained from the concerned hospital authorities to conduct the proposed study. Then the researcher contacted with autistic children and their mother's who met the inclusion criteria for their informed consent.

-Data were collected over a period of 6 months from the beginning of April, 2018 up to the end of September, 2018 using the previously mentioned tools.

-Every mother was interviewed individually, after explaining the purpose of the study and getting agreement on the mother to participate in the study. The investigator assured voluntary participation and confidentiality for each subject who agreed to participate. In this study the questionnaire was read and explained to every participant and the choices was recorded by the researcher.

-For more validation of the mother's information, the child was asked to revise and complete the needed information.

-Pre-post tools of assessment was utilized to collect data. In case of the inability of the participants to read and write they were filled by the researcher. All steps of the program were carried out by the researcher.

\section{Program phases:}

\section{Preparatory phase}

\section{a. Preparation of the content:}

The content of the program based on related literature- the planning phase includes the program strategy (time table, teaching methods and materials used). The content of the program includes an introduction of basic knowledge related to ASD as sources of ASD information, prevalence, causes, identifying children with ASD, symptoms and behaviors exhibited by children of ASD and misconceptions regarding the nature of treatment and its side effects along with prognosis. Strategy for giving successful instructions to children with ASD, needed mothers' skills to help children with ASD and effective behavioral strategies to deal with ASD children. The researchers used discussion, role play, feedback and presentation to 
help the mothers. They also used effective behavioral strategies with children.

\section{b. Assessment and data collection (pretest):}

All mothers completed the pre-study scale before the beginning of the program. This assessment was completed through mothers' self-report.

\section{Introductory phase ( 2 sessions):}

Initially an acquaintance between researchers and mothers was made, brief explanations about program aim, numbers of sessions, meeting time, data of each session, program rules, expected outcomes, and benefits of program participation.

\section{Implementation phase (12 sessions):}

In this stage, researchers started program sessions. The meetings were two times per week at the same time and in the same room for 45-60 minutes each session.

Researchers used open-ended questions, warmth and concern with mothers to ensure that they reached the objective of each session, each session started by a feedback about the previous one.

\section{Evaluation phase (last session):}

Mothers were reassessed by using the same tools of pretest to compare and determine the effectiveness of the program evaluation.

\section{Pilot study:}

A Pilot study was carried out on 5 mothers $(10 \%)$ of the target population (45) to ensure the clarity and applicability of the study tools. Subjects who participated in the pilot study will be excluded from the actual study.

\section{Ethical consideration:}

To carry out the study ethical consideration to ensure that participants' rights were maintained, the necessary official approval was obtained from the Faculty of Nursing Fayoum University Administration to collect the necessary data after explaining the purpose of the study. The aim of the study was explained to each mother having an autistic child and written informed consent was obtained to participate. All mothers having autistic child were assured that the obtained information will be confidential and will be used only for the purpose of the study.

\section{Statistical analysis:}

The data were coded, tabulated and analyzed using SPSS version (21) qualitative data were expressed as number and percentage, and the Chi-square test was applied to test the relationship between variables. Quantitative data were expressed as mean and standard deviation (Mean \pm SD) and the Person correlation test was applied to test the relationship between quantitative variables. A $P$-value of $<0.05$ was considered as statistically significant.

\section{RESULTS}

Table 1: Mothers' characteristics in the study sample $(n=45)$

\begin{tabular}{|c|c|c|}
\hline Parents' characteristics & No & Percent \\
\hline \multicolumn{3}{|l|}{ Mothers' age } \\
\hline$<20$ & 4 & 8.9 \\
\hline $20+$ & 25 & 55.6 \\
\hline $30+$ & 16 & 35.5 \\
\hline $40+$ & 0 & \\
\hline \multicolumn{3}{|l|}{ Mothers' education } \\
\hline Illiterate & 15 & 33.3 \\
\hline Read/write/basic & 13 & 28.9 \\
\hline Secondary & 7 & 15.6 \\
\hline University & 10 & 22.2 \\
\hline \multicolumn{3}{|l|}{ Mothers' job } \\
\hline Housewife & 37 & 82.2 \\
\hline Working & 8 & 17.8 \\
\hline \multicolumn{3}{|l|}{ Social status } \\
\hline Co-living & 33 & 73.3 \\
\hline Separated/divorced & 11 & 24.4 \\
\hline Widowed & 1 & 2.2 \\
\hline \multicolumn{3}{|l|}{ F amily income } \\
\hline $\begin{array}{l}\text { Sufficient and } \\
\text { saving }\end{array}$ & 5 & 11.1 \\
\hline Sufficient & 26 & 57.7 \\
\hline Insufficient & 14 & 31.2 \\
\hline \multicolumn{3}{|l|}{ Family number } \\
\hline$<4$ & 21 & 46.6 \\
\hline $4-6$ & 23 & 51.2 \\
\hline$>6$ & 1 & 2.2 \\
\hline \multicolumn{3}{|l|}{ Place Residence } \\
\hline Urban & 11 & 24.5 \\
\hline Rural & 34 & 75.5 \\
\hline
\end{tabular}


Table 1 showed mothers' characteristics. Concerning mothers' age, more than half $(55.6 \%)$ of the mother's age were ranging from 20 to 30 years. Regarding the educational level of mothers, $33.3 \%$ were illiterate. This table also shows that the highest percentages of mothers were housewives $(82.2 \%)$. The table also clarifies that less than three quarters of children have parents living together. More than half of the sample $(57.7 \%)$ had sufficient income. More than half of the sample (51.2\%) had 4-6 member in the family and three quarters of the sample $(75.5 \%)$ were residing in rural areas.

Table 2: Distribution of children with Autism disorders, according to their characteristics in the study sample $(n=45)$

\begin{tabular}{|c|c|c|}
\hline Child's characteristi cs & No & $\%$ \\
\hline \multicolumn{3}{|l|}{ Child's age } \\
\hline $2<6$ & 25 & 55.5 \\
\hline $6<12$ & 20 & 44.5 \\
\hline $12-$ & 0 & 0.0 \\
\hline Mean \pm SD & \multicolumn{2}{|c|}{$5.8 \pm 2.5$} \\
\hline \multicolumn{3}{|l|}{ Gender } \\
\hline Male & 19 & 41.3 \\
\hline Female & 26 & 57.7 \\
\hline \multicolumn{3}{|l|}{ No. of siblings } \\
\hline 1 & 6 & 13.3 \\
\hline $2+$ & 39 & 86.7 \\
\hline Range & \multirow{2}{*}{\multicolumn{2}{|c|}{$\begin{array}{l}1-5 \\
2.4 \pm 1.05\end{array}$}} \\
\hline Mean \pm SD & & \\
\hline \multicolumn{3}{|l|}{ Birth order } \\
\hline $1^{\mathrm{st}}$ & 18 & 40.0 \\
\hline $2^{\mathrm{nd}_{+}}$ & 27 & 60.0 \\
\hline
\end{tabular}

Table 2 showed distributions of children with Autistic disorder, according to their characteristics in the study sample. This table showed that $55.5 \%$ of the studied children' age ranged from 2 to 5 years, $57.7 \%$ of them were females. Number of siblings was more than two in $86.7 \%$ of the studied sample and three fifth of children $(60 \%)$ ranked as the second child in the family.

Table 3: Distributions of children with Autism disorder, according to their educational history in the study sample $(n=45)$

\begin{tabular}{|l|r|c|}
\hline Children's History & No & \% \\
\hline Attended nursery & 25 & 55.5 \\
\hline Yes & 20 & 44.5 \\
\hline No &
\end{tabular}

Has nursery problems due to his disease $\mathrm{N}=25$

\begin{tabular}{|l|l|l|}
\hline Yes & 16 & 64.0 \\
\hline No & 9 & 36.0 \\
\hline
\end{tabular}

Wasdismissed due to his condition $\mathrm{N}=16$

\begin{tabular}{|c|c|c|}
\hline Yes & 7 & 43.8 \\
\hline No & 11 & 56.2 \\
\hline
\end{tabular}

Study level in nursery school $\mathbf{N}=11$

\begin{tabular}{|l|l|l|}
\hline High & 1 & 9.1 \\
\hline Middle & 6 & 54.5 \\
\hline Low & 4 & 36.4 \\
\hline Attended school & & \\
\hline Yes & 20 & 44.5 \\
\hline No & 25 & 55.5 \\
\hline
\end{tabular}

Has school problems due to his condition $\mathbf{N}=\mathbf{2 0}$

\begin{tabular}{|c|c|c|}
\hline Yes & 6 & 30.0 \\
\hline No & 14 & 70.0 \\
\hline Study level in school & $\mathbf{N = 1 4}$ & \\
\hline High & 1 & 7.2 \\
\hline Middle & 10 & 71.4 \\
\hline Low & 3 & 21.4 \\
\hline
\end{tabular}

Table 3 shows that more than half of study children $(55.5 \%)$ attended nursery school, $64 \%$ of them had problems due to his disease and $43.8 \%$ were dismissed due to their conditions and $54.5 \%$ of children that does not have problems in primary school, were in middle school.

Concerning the school attendance, less than half of children (44.5\%), attended school, $70 \%$ of them did not face problem at school due to their condition and the majority of them $(71.4 \%)$ were mediocre in their learning standard. 
Table 4: Dependency in activities of daily life (ADLs) among Autistic children as reported by mothers' throughout the program phases $(n=45)$

\begin{tabular}{|c|c|c|c|c|c|}
\hline \multirow{4}{*}{ Daily life activities ${ }^{a}$} & \multicolumn{4}{|c|}{ Phase (s) } & \multirow{4}{*}{$\begin{array}{l}X^{2} \text { Test } \\
P \text {-value } \\
\text { Pre -post }\end{array}$} \\
\hline & \multicolumn{4}{|c|}{$\mathrm{N}=45$} & \\
\hline & \multicolumn{2}{|c|}{ Pre Intervention } & \multicolumn{2}{|c|}{ Post Intervention } & \\
\hline & No & $\%$ & No & $\%$ & \\
\hline $\begin{array}{l}\text { Eating/drinking : } \\
\text { - Dependent } \\
\text { - Partially dependent } \\
\text { - Independent }\end{array}$ & $\begin{array}{l}23 \\
19 \\
3\end{array}$ & $\begin{array}{l}51.1 \\
42.2 \\
6.7\end{array}$ & $\begin{array}{l}12 \\
10 \\
23\end{array}$ & $\begin{array}{l}26.7 \\
22.2 \\
51.1\end{array}$ & $<0.001 *$ \\
\hline $\begin{array}{l}\text { Wearing clothes and general appearance: } \\
\text { - Dependent } \\
\text { - Partially dependent } \\
\text { - Independent }\end{array}$ & $\begin{array}{l}26 \\
17 \\
2\end{array}$ & $\begin{array}{l}57.8 \\
37.8 \\
4.4\end{array}$ & $\begin{array}{l}11 \\
8 \\
26\end{array}$ & $\begin{array}{l}24.4 \\
17.8 \\
57.8\end{array}$ & $<0.001^{*}$ \\
\hline $\begin{array}{l}\text { Personal hygiene (dental care, bathing): } \\
\text { - Dependent } \\
\text { - Partially dependent } \\
\text { - Independent }\end{array}$ & $\begin{array}{l}25 \\
19 \\
1\end{array}$ & $\begin{array}{l}55.6 \\
42.2 \\
2.2\end{array}$ & $\begin{array}{l}13 \\
12 \\
20\end{array}$ & $\begin{array}{l}28.9 \\
26.7 \\
44.4\end{array}$ & $<0.001 *$ \\
\hline $\begin{array}{l}\text { Elimination (urinate, defecate): } \\
\text { - Dependent } \\
\text { - Partially dependent } \\
\text { - Independent }\end{array}$ & $\begin{array}{l}24 \\
20 \\
1\end{array}$ & $\begin{array}{l}53.3 \\
44.5 \\
2.2 \\
\end{array}$ & $\begin{array}{l}10 \\
7 \\
28\end{array}$ & $\begin{array}{l}22.2 \\
15.6 \\
62.2\end{array}$ & $<0.001^{*}$ \\
\hline $\begin{array}{l}\text { Total activities: } \\
\text { - Dependent } \\
\text { - Partially dependent } \\
\text { - Independent }\end{array}$ & $\begin{array}{l}31 \\
14 \\
0 \\
\end{array}$ & $\begin{array}{l}68.9 \\
31.1 \\
0.0 \\
\end{array}$ & $\begin{array}{l}7 \\
8 \\
30 \\
\end{array}$ & $\begin{array}{l}15.6 \\
17.8 \\
66.6 \\
\end{array}$ & $<0.001^{*}$ \\
\hline
\end{tabular}

(a) More than one answer

The effect of the implementation of the program on children with ADLs is described in this table. At the preimplementation phase, the majority of children were dependent regarding their clothing (57.8\%) and 55.6\% in hygienic measures. After implementation of the program, statistically significant improvements were noticed $(p<0.001)$. Where on the post implementation phase, only few of them were fully dependent and most of them were independent inspite of ADL

Table 5: Comparison between pre-post intervention as regards mothers' knowledge related to their children with Autism in the study sample $(n=45)$

\begin{tabular}{|c|c|c|c|c|c|c|}
\hline \multirow{3}{*}{ Satisfactory Knowledge $(50 \%+)$} & \multicolumn{4}{|c|}{ Protocols } & \multirow{3}{*}{ CHI } & \multirow{3}{*}{$\boldsymbol{P}$} \\
\hline & \multicolumn{2}{|c|}{ Pre } & \multicolumn{2}{|c|}{ Post } & & \\
\hline & No & $\%$ & No & $\%$ & & \\
\hline Definition & 17 & 37.8 & 38 & 84.4 & & \\
\hline $\begin{array}{l}\text { Etiology } \\
\text { Psychological, genetic, physical, environmental and } \\
\text { nutritional }\end{array}$ & 21 & 46.7 & 42 & 93.3 & & \\
\hline
\end{tabular}




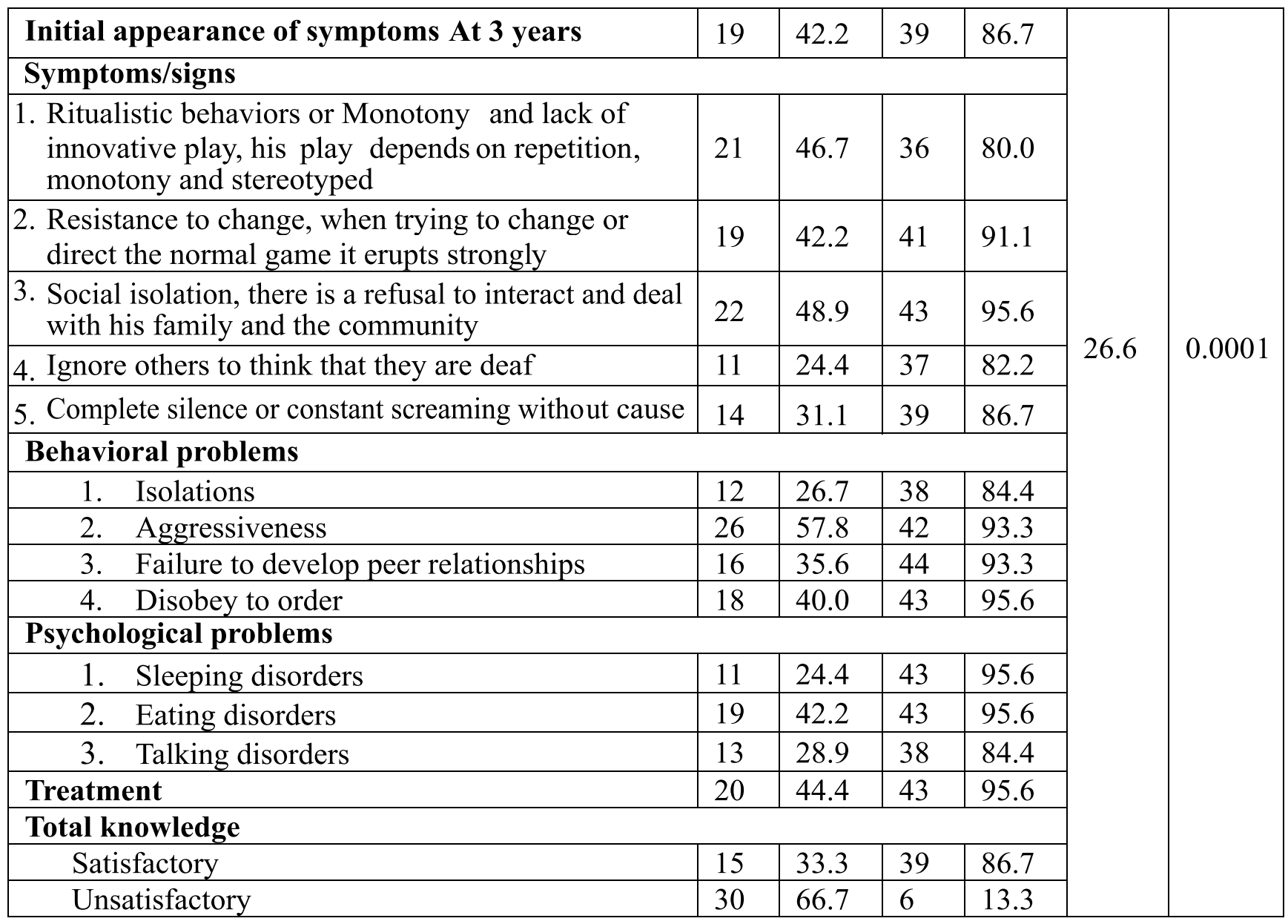

Table 5 clarified that, at pre-program stage most mothers had inadequate knowledge about Autism. As one third of mothers only had satisfactory knowledge about autism (33.3\%), but their knowledge was upgraded after the implementation of the program. About $86.7 \%$ of mothers had satisfactory knowledge about the definition, etiology, symptoms/signs, behavioral problems, psychological problems, treatment with a highly statistically significant difference $(2=26.6$ at $P<0.001)$.

Table 6: Psychological and social problems among parents having an Autistic child (N=45)

\begin{tabular}{|c|c|c|c|c|c|c|}
\hline \multirow{3}{*}{ Pressures } & \multicolumn{4}{|c|}{ Protocols } & \multirow{3}{*}{ Chi } & \multirow{3}{*}{$P$} \\
\hline & \multicolumn{2}{|l|}{ Pre } & \multicolumn{2}{|c|}{ Post } & & \\
\hline & No & $\%$ & No & $\%$ & & \\
\hline \multicolumn{7}{|l|}{ Psychological } \\
\hline Mild & 11 & 24.5 & 24 & 53.3 & \multirow{3}{*}{9.4} & \multirow{3}{*}{0.008} \\
\hline Moderate & 15 & 33.3 & 13 & 28.9 & & \\
\hline Severe & 19 & 42.2 & 8 & 17.8 & & \\
\hline \multicolumn{7}{|l|}{ Social } \\
\hline Mild & 6 & 13.3 & 18 & 40.0 & \multirow{3}{*}{8.2} & \multirow{3}{*}{0.016} \\
\hline Moderate & 19 & 42.2 & 14 & 31.1 & & \\
\hline Severe & 20 & 44.5 & 13 & 28.9 & & \\
\hline
\end{tabular}


Table 6 revealed that about two fifth $(42.2 \%)$ of the mothers with severe psychological problems in the pretest declined to $17.8 \%$ in the post test. Also, $44.5 \%$ of mothers had severe social problems in the pretest which declined to become $28.9 \%$ in the post test.

Table 7: Comparison between pre-post interventions as regards mothers' coping pattern to decrease their psychological stressors $(n=45)$

\begin{tabular}{|c|c|c|c|c|c|c|}
\hline \multirow{2}{*}{ Coping Pattern } & \multicolumn{2}{|l|}{ Pre } & \multicolumn{2}{|c|}{ Post } & \multirow{2}{*}{ CHI } & \multirow{2}{*}{$P$} \\
\hline & No & $\%$ & No & $\%$ & & \\
\hline Doing exercise & 12 & 26.7 & 37 & 82.2 & \multirow{6}{*}{30.7} & \multirow{6}{*}{0.00001} \\
\hline Doing the relaxed breathing exercises. & 15 & 33.3 & 43 & 95.6 & & \\
\hline Doing the exercise of intellectual muscle relaxation & 9 & 20.0 & 39 & 86.7 & & \\
\hline Doing exercise of affirmative behavior training & 7 & 15.6 & 38 & 84.4 & & \\
\hline Exercise time management training & 13 & 28.9 & 42 & 93.3 & & \\
\hline $\begin{array}{c}\text { Total practice: } \\
\text { Adequate } \\
\text { Inadequate }\end{array}$ & $\begin{array}{l}13 \\
32\end{array}$ & $\begin{array}{l}28.9 \\
71.1\end{array}$ & $\begin{array}{l}36 \\
9\end{array}$ & $\begin{array}{l}80.0 \\
20.0\end{array}$ & & \\
\hline
\end{tabular}

Table 7 indicated that there was a highly statistically significant difference between pre and post program as regards the total scores of mothers' coping pattern to decrease their psychological stressors, which improved in post program from $28.9 \%$ to $80 \%,(\mathrm{CHI}=30.7, p<0.0001)$.

Table 8: Comparison between pre-post interventions as regards mothers' behavior towards their children with Autism in the study sample $(n=45)$

\begin{tabular}{|c|c|c|c|c|c|c|}
\hline \multirow{2}{*}{ Behavior } & \multicolumn{2}{|c|}{ Pre } & \multicolumn{2}{|c|}{ Post } & \multirow[t]{2}{*}{ CHI } & \multirow{2}{*}{$\boldsymbol{P}$} \\
\hline & No & $\%$ & No & $\%$ & & \\
\hline Teaching methods of communications to the child & 27 & 62.8 & 42 & 93.3 & \multirow{12}{*}{11.6} & \multirow{12}{*}{0.0006} \\
\hline Using pointing language & 11 & 24.4 & 40 & 88.9 & & \\
\hline Using repetition of words and recording & 2 & 4.4 & 38 & 84.4 & & \\
\hline Teaching him how to use pictures & 13 & 28.9 & 37 & 82.2 & & \\
\hline Punishment \& positive reinforcement & 16 & 35.6 & 41 & 91.1 & & \\
\hline Training about toileting in the W.C & 23 & 51.1 & 39 & 86.7 & & \\
\hline Self_protection against abuse & 16 & 35.6 & 41 & 9.2 & & \\
\hline $\begin{array}{l}\text { Behavior during angry and agitation } \\
\text { Achieve his/her desires }\end{array}$ & 19 & 42.2 & 42 & 93.3 & & \\
\hline Dietary treatment therapy & 5 & 11.1 & 34 & 75.6 & & \\
\hline Behavioral treatment therapy & 8 & 17.8 & 31 & 68.9 & & \\
\hline Use play treatment method & 14 & 31.1 & 39 & 86.7 & & \\
\hline $\begin{array}{c}\text { Total practice: } \\
\text { Adequate } \\
\text { Inadequate }\end{array}$ & $\begin{array}{l}18 \\
27\end{array}$ & $\begin{array}{l}40.0 \\
60.0\end{array}$ & $\begin{array}{l}34 \\
11\end{array}$ & $\begin{array}{l}75.6 \\
24.4\end{array}$ & & \\
\hline
\end{tabular}

Table 8 revealed that there were highly statistically significant differences between pre and post program as regards to mothers' behavior towards their children with Autism. There behavior improved in post program (from $60.0 \%$ to $24.4 \%$ ). 
Table 9: Correlation matrix between the studied variables post-program among studied sample $(n=45)$

\begin{tabular}{|l|c|c|c|c|c|}
\hline $\begin{array}{l}\text { Study } \\
\text { variables }\end{array}$ & Knowledge & Behaviors & $\begin{array}{c}\text { Mothers' } \\
\text { burden }\end{array}$ & $\begin{array}{c}\text { Coping } \\
\text { pattern }\end{array}$ & $\begin{array}{c}\text { Daily living } \\
\text { activates }\end{array}$ \\
\hline Knowledge & 1 & & & & \\
\hline Behaviors & $0.605^{* *}$ & 1 & & & \\
\hline $\begin{array}{l}\text { Mothers' } \\
\text { burden }\end{array}$ & $0.745^{* *}$ & $0.619^{* *}$ & 1 & & \\
\hline $\begin{array}{l}\text { Coping } \\
\text { pattern }\end{array}$ & $0.736^{* *}$ & $0.812^{* *}$ & $0.618^{* *}$ & 1 & \\
\hline $\begin{array}{l}\text { Daily living } \\
\text { activates }\end{array}$ & $0.840^{* *}$ & $0.663^{* *}$ & $0.629^{* *}$ & $0.692^{* *}$ & 1 \\
\hline
\end{tabular}

** Correlation is significant at 0.001 levels

Table 9 revealed that, there was statistically significant positive correlations between mothers' behaviors and knowledge, where $r=0.605$. Also, there were statistically significant positive correlations between mothers' burden, knowledge, and behavior, where $r=00.745$ and 0.619 respectively. Furthermore, statistically significant positive correlations were found between coping patterns, knowledge, behaviors and burden where $r=0.736 \& 0.812,0.618$ respectively. Also, there were statistically significant positive correlations between daily living activities, knowledge, behaviors, burden and coping patterns among the studied mothers where $(r=0.840,0.663,0.629 \& 0.692)$ respectively.

\section{DISCUSSION}

Autism is a complex neurodevelopmental disorder characterized by core deficits in three major domains namely social interaction, communication and behaviors. These deficits are usually noted before 3 years of life (Benson \& Karlof, 2010). This study aimed to assess, plan, implement and evaluate the effect of educational program on cognitive-behavior among mothers to reduce the mothers' burden of care towards their children with autism.

The study revealed that the mean age of children was $5.8 \pm 2.5$ years. In support of this result the study carried out by Amr et al., (2012) revealed that the children mean age were 2-6 years.

Regarding mothers' age, it ranged from 20-30 years old. The findings of the present study are nearly in agreement with Lendenmann, 2010, who showed that the participants ranged in age from 22 to 30 years old.
As for mothers' characteristics, it was noticed that about less than half of mothers were highly educated, with a university degree. Based on the present study finding, this might be explained by the fact that autism as a disease is difficult to be noticed by uneducated parents. Meanwhile, it was found that high level of education might have a positive impact mother's effort and management of the autistic child. This finding was in agreement with Keen et al., (2010) who reported that more than third of the parents have completed four years of college, also more than a third held master degree, and less than one quarter held a doctoral and professional degree. Similarly, Elsebaie (2012) found that more than half of the parents of autistic children had higher education.

Regarding mothers' education, the current study portrayed that there were about two thirds of the studied group were educated (Read/Write, Basic, Secondary and University) although the high percentage of them were not working and preferred to stay home to take care of their children. Also, this may be due to that mothers have to spend a part of their effort and time to meet the demands of medical treatment such as taking the child to a psychiatric clinic, giving medication in time, and follow up the child's condition continuously.

This result was in contradiction with Kuhn \& Carter, (2010) who reported that the majority of mothers of autistic children were illiterate and higher percentage of them were housewives. This finding was in congruence with Koydemir \& Tosun (2009), who reported that, the majority of mothers of autistic children were working.

Regarding the age of children with autism, the present study revealed that, slightly more than half of the studied children age ranged from two to five years. These findings were consistent with the study reported by Amr et al., (2012) who stated that the mean age of the total sample was four with a range from two to seven years. Also, it was congruent with Abd El- Haliem et al., (2013) who found that, the ages of the children ranged from three to six years with a mean age of four years.

The present study illustrated that slightly more than half of children with autism were females, which constitute a big problem for their future possibility of getting married and consequences would affect their 
daily lives. This finding was in disagreement with a study by Hayward et al., (2011) who found that males are several times more likely to be affected by autism than females. Current estimates of the number of male to female children with autism ranged between 3 to 1 and 4 to 1 and these gender differences are fairly consistent across ethnicities (Center for Disease Control and Prevention, 2014). Also, these findings are supported by Abd El-Haliem et al., (2013) who showed that the majority of children were males; this result agreed with El-Bahnasawy \& Girgis, (2011) who found that, more than two thirds of children with autism were boys.

In this respect, the current study revealed that the mean and standard deviation of siblings were $2.4 \pm 1.05$ where, most of the sample was ranked as the second child in the family. This result was nearly inconsistent with the study by Abd El-Maaboud (2016) who illustrated that, the mean and standard deviation for numbers of sibling were $2.6 \pm 1.337$ with a range from $(0-6)$.

Results of the present study clarified that, nearly more than a ninth of the studied children with autism ranked as first child in the family, this result agreed with Mansour, (2010) who reported that, the highest percentage of children with autism ranked as the first child in the family, while this result did not agree with Elsebaie, (2012) who observed that, one third of the studied children ranked as the second child in the family.

As regards to family history of mental illness, the result of the studied families showed that, most of the parents had a negative family history of mental illness, while less than one quarter had positive family history of mental illness. Based on the finding of the current study, high positive family history in Egypt may be due to the tendency of the families to stop birth after the diagnosis of an affected child.

The present study showed that, the majority of the sample has highly statistically significant difference $\left(\chi^{2}=26.6\right.$ at $\left.P<0.001\right)$ regarding their knowledge about Autism pre and post program. However, in postprogram, answers of mothers regarding knowledge about the definition, etiology, symptoms/signs, behavioral and psychological problems, treatment were enhanced because the mothers needed ways to deal with their autistic children having. In the present study, the mothers were young and have more time because they were housewives. This result was supported by a study carried out by Lopez et al., (2011) who observed that, nearly two thirds of mothers having children with autism having statistically significant differences regarding their knowledge about Autism. As mentioned by Glen et al., (2010) who stated that more than half of the mothers having child with autism gain knowledge about the Autism after program intervention.

On this respect, the results of the current study illustrated that less than half of mothers faced severe psychological problems before intervention than after the program, more than half the sample suffered from mild degree of problem. The mothers who faced social problems from their children with autism before the program were slightly less than half. They faced severe degree of the problem, before the program and after the program less than half of mothers had mild degree of anxiety. Children with autism are typically characterized by a lack of social connectedness and face difficulties with communication. So their mothers have to stay with their children seperating them from the society to avoid embarrassment. In addition, mothers have social isolation as well as financial needs, suffer from the unavailability of suitable treatment for their children, suffer from high cost of medications and suffer from high prices of rehabilitation centers which can contribute to reduced well being of the mothers and elevated psychosocial problems. This result is supported by Wiener (2010) who clarified that, two thirds of the mothers faced psychological and social problems for their children with autism; they improved their status and gain more tolerance to face their problem after intervention.

The results revealed that, mothers of autistic children suffer from stress as there is no sufficient time to relax, their leisure activity decreased as they have to take care of their autistic child. The child need partial or complete assistance in performing daily activities (like personal hygiene, elimination, wearing clothes, selffeeding and communication). However after the program intervention more than two thirds of the mothers applied new pattern of quality of life, such as doing exercise, performing relaxed breathing exercises, doing muscle relaxation exercise, doing exercise of assertiveness behavior training and time management. Stress and social problems could have a negative impact on mothers, leading to depression, anger, anxiety and 
marital relationship disorder.

This finding was in agreement with Abbeduto et al., (2014), Baker- Ericzen et al., (2005) and Yamada et al., (2007); they found that, mothers with autism reported significantly more stress and lower level of well-being than mothers of children with other disabilities. In addition, mothers of children with autism reported lower levels of quality of life. In agreement with this finding, Koydemir \& Tosun, (2009) stated that the majority of mothers having children with autism experienced more stress and felt financial exhaustion beside stress.

Knowledge support is one of the coping pattern used by mothers because nearly more than two thirds of mothers have someone who provides them with information about the illness, someone advises them to take their children to hospital and someone provides solution to their problems like teaching methods of communications to the child, using pointing language, using repetition of words and recording, teaching how to use pictures, punishment and positive reinforcement, training about toileting and self-protection against abuse; some advises them about daily living, also some discusses and plans the future with them. After the program most of the studied sample revealed that, there was a highly statistically significant difference between pre- and post-program as regards to inadequate total score of change of mothers' practice toward children with autism.

This result was in agreement with Major, (2003) who emphasized that mothers need to share information with others in order to feel comfortable. In the same line, Boyd, (2002) reported that, mothers of children with disabilities are constantly in need for information about their child and how to deal with defective behavior and attitude.

As regards the actual support, regarding coping method used by mothers, the findings of the current study revealed that mothers need support in the area to help them to do some exercise, followed by someone who can help them to get away from the psychological difficulty. In the same line, Luther et al., (2005) found that, support groups benefited mothers not only by giving them a place to discuss their difficulties but also to share coping strategies and accomplishments, and to meet other mothers in the similar situation which helped them to cope and reduce stress.

The need for maintaining stability turned to be an important coping pattern used by mothers in the present study. The majority of the sample agreed upon avoiding stress and taking medication. This may be due to the high need to reduce the burden of mothers when give care to their children with autism disease. On the same line, Lin et al., (2008) stated that, the self-change adjustments were made by mothers of autistic children as coping pattern.

However, the finding was incongruent with the World Health Organization, which reported that people often cope with the negative emotions elicited by stress through behaviors that bring short term relief but carry long term risks. Under stress, people generally smoke more; drink more alcohol, eat foods with a higher fat and sugar content and exercise less (WHO, 2013).

This study results revealed that, there was a highly positive correlation between all study variables. This study revealed that teaching autistic children to do their daily living activities independently is effective in reducing the burden of the mothers to some extent. In agreement with the current study result Green \& Carter (2014) showed that the daily living skills and parenting stress appeared to get slightly stronger over time.

\section{CONCLUSION}

This study concluded that the prevalence of autism was much higher among females in this Egyptian sample. There was statistically significant differences pre and post program between the level of mothers' knowledge, skills and behavior. There was a highly statistically significant difference between pre and post program as regards to the total scores of mothers' coping pattern to decrease their psychological and social stresses, which improved in post program. There were statistically significant positive correlations between parents' burden and the child's capability to perform daily living activities among studied group.

\section{RECOMMENDATIONS}

Based on the present study, the following recommendations can be suggested:

- Educational programs to increase mothers' knowledge and awareness about the nature of autism. 
- There is an urgent need to encourage the formation of support groups to help parents connected to other parents of autistic children who have similar problems and concerns.

- Counseling clinics for parents with autistic children are needed to ensure an effective response to the needs of autistic children and their families.

- Research to identify the effectiveness of nursing interventions to enhance the use of coping strategies among parents of autistic children.

- $\quad$ Programs for parents of children with autism, such as a stress management technique.

\section{REFERENCES}

Abbeduto, L., Seltzer, M.M., Shattuck, P., Krauss, M.W., Orsmond, G. \& Murphy, M.M. (2014). Psychological well-being and coping in mothers of youth with autism, Down syndrome, or Fragile X syndrome. American Journal on Mental Retardation, 109(3), pp 237-254.

Abd El-Haliem, E.K., Sharka, S.A., Mobarak, A.A. \& Mohamed, N.T. (2013). Study of eating Habits for Children with Autism at Assuit City. Journal of American Science, 9(11), pp 485-496.

Amr, M., Al Bu Ali, W., Raddad, D., El-Mehesh, F., El-Gilany, A-H. \& Al Shamy, H. (2012). Sociodemogrghic factors in Arab Children with Autism Spectrum Disorders. Pan African Medical Journal, 13:65.

Baker, B.L., Blacher J. \& Olsson, M.B. (2005). Preschool children with and without developmental delay: Behavior problems, Parents' optimism and well being. Journal of Intellectual Disability Research, 49(Pt 8), pp 575-590.

Benson, P. \& Karlof, K.L. (2010). Anger, stress proliferation, and depressed mood among parents of children with ASD: A longitudinal replication. Journal of Autism and Developmental Disorders, 39(2), pp 350-362.

Biligin, H. \& Kucuk, L. (2010). Raising an autistic child: perspectives from Turkish mothers. Journal of Child and Adolescent Psychiatric Nursing, 23(2), pp 92-99.

Boyd, B.A. (2002). Examining the relationship between stress and lack of support in mothers of children with autism. Focus on Autism and other Developmental Disabilities, 17(4), pp 208-215.

Carmichael, M. (2016). Increasing rates of autism diagnosis, a nurse role. Journal of Developmental and Behavioral Pediatrics, 27(2), pp 437-447.

Center for Disease Control and Prevention (2014). Retrieved from: http://ASD.cdc.gov/ncbddd/autism/index.html.

El-Bahnasawy, T. \& Girgis, M. (2011). Counseling for Mothers to cope with their Autistic Children. Journal of American Science, 7(7), pp 183-192.

Elsebaie, S.R. (2012). Stress and coping pattern among parents having children with autism, Faculty of nursing, Zagazig University, Egypt.

Filipek, P.A., Accardo, P.J., Ashwal, S., Baranek, G.T., Cook, E.H. Jr, Dawson, G., Gordon, B., Gravel, J.S., Johnson, C.P., Kallen, R.J., Levy, S.E., Minshew, N..J, Ozonoff, S., Prizant, B.M., Rapin, .I, Rogers, S.J., Stone, W.L., Teplin, S.W., Tuchman, R.F. \& Volkma, F.R. (2000). Practice parameter: screening and diagnosis of autism: report of the Quality Standards Subcommittee of the American Academy of Neurology and the Child Neurology Society. Neurology, 55(4), pp 468-79.

Gilham, J., Carter, A., Volkmar, R. \& Sparrow, S. (2011). Toward a Developmental Operational definition of autism. Journal of Autism and Developmental Disorder, 30(4), pp 269-278.

Glen, I., Probst, P., Spritz, J. \& Jung, F. (2010). An Evaluative study of the social validity of the developmental disability, parent training program Stepping Stones Triple P. Life Span \& Disability, 13(1), pp 43-70. 
Green, S. \& Carter, A. (2014). predictors and course of daily living skills development in toddlers with Autism Spectrum Disorders. Journal of Autism and Developmental Disorders, 44(2), pp 256-263.

Hafiz, M. (2007). Study about the problem size of autism in Egypt. Pediatric Medicine, National Commission for childhood, Studies and Research Forum.

Hayward, D., Eikeseth, S., Gale, C. \& Morgan, S. (2009). Assessing progress during treatment for young children with autism receiving intensive behavioural interventions. Autism, 13(6), pp 613-633.

Howlin, P. (2017). Outcomes in Autism Spectrum Disorders. In Volkmar, R., Paul, R., Kiln, A., Cohen, D., Handbook of Autism and Pervasive Developmental Disorders, $3^{\text {rd }}$ edition, (Vol. II.) Hoboken, N: John Wiley \& Sons, pp 201-220.

Keen, D., Couzens, D., Muspratt, S. \& Rodger, S. (2010). The effects of a parent focused intervention for children with a recent diagnosis of autism spectrum disorder on parenting stress and competence. Research in Autism Spectrum Disorders, 4(2), pp 229-241.

Koydemir, S. \& Tosun U. (2009). Impact of autistic children on the lives of mothers. Procedia Social and Behavioral Sciences, 1(1), pp 2534-2540.

Kuhn, C.J. \& Carter, A.S. (2010). Maternal self-efficacy and associated parenting cognitions among mothers of children with autism. American Journal of Orthopsychiatry, 76(4), pp 564-75.

Lendenmann, M.M. (2010). The lived. Experience of Parenting a preschool Age, Moderately Mental Retarded Autistic Child. A Dessartation submitted to the Faculty of the School of Nursing of The Catholic University of America, USA.

Levenstein, S., Prantera C., Varvo V., Scribano, M.L., Berto, E., Luzi, C. \& Andreoli, A. (1993). Development of the Perceived Stress Questionnaire: A new tool for psychosomatic research. Journal of Psychosomatic Research, 37(1), pp 19-32.

Lin, C.R., Tsai, Y.F. \& Chang, H.L. (2008). Coping mechanisms of parents of children recently diagnosed with Autism in Taiwan: a qualitative study. Journal of Clinical Nursing, 17(20), pp 2733-2740.

Liss, M., Fein, D., Allen, D. \& Feinstein, C., Morris, R., Waterhouse, L. \& Rapin, I. (2011). Executive functioning in high functioning children with Autism. Journal of child Psychology and Psychiatry, 42(2), pp 261-270.

Lopez-Wagner, M.C., Hoffman, C.D., Sweeney D.P., Hodge, D. \& Gilliam J.E. (2011). Sleep problems of parents of typically developing children and parents of children with autism. The Journal of Genetic Psychology, 169(3), pp 245-259.

Luther, E., Canham, D. \& Cureton, V. (2005). Coping and social support for parents of children with autism. Journal of School Nursing, 21(1), pp 40-47.

Major, A.D. (2003). Utilizing role therapy to help employed parents cope with children's chronic illness. Health Education Research,18(1), pp 45-57.

Mandell, D.S., Cao, J., Ittenbach, R. \& Pinto-Martin, J. (2006). Medicaid expenditures for children with autistic spectrum disorders: 1994 to 1999. Journal of Autism and Developmental Disorders, 36(4), pp 475-485.

Mansour, K. (2010). Parent awareness regarding care of their children suffering from Autism. Unpublished Master's Thesis, University of Ain-Shams, Cairo, Egypt.

Matson, J. \& Rivet, T. (2016). The effects of severity of Autism on challenging behaviors in children with intellectual disabilities. Journal of Autism and Intellectual Disability, 20(3), pp 41-51. 
Perry, A., Flanagan, H, Geier, D. \& Freeman, N. (2009). Brief report: The Vineland Adaptive Behavior Scales in young children with autism spectrum disorders at different cognitive levels. Journal of Autism and Developmental Disorders, 39(7), pp 1066-1078.

Sawyer, M.G., Bittman, M., LaGrecca, A.M., Crettenden, A.D., Harchak, T.F. \& Martin, J. (2012). Time demands of caring for children with autism: What are the implications for maternal mental health? Journal of Autism and Developmental Disorders, 40(5), pp 620-62.

Wiener, C.L. (2010). The burden of Autism. In Strauss, A. Et, (Eds) Chronic Illness and the Quality of Life (2 ${ }^{\text {nd }}$ edition) St. Louis: The C.V. Mosby Company.

Wood, J. (2012). Parental Intrusiveness and Children's Separation Anxiety in A Clinical Sample. Child Psychiatry and Human Development, 37(1), pp 73-87.

World Health Organization (2013). Autism Spectrum Disorder and other developmental Disorder: from raising awareness to building capacity.

Yamada, A., Suzuki, M., Kato, M., Suzuki, M., Tanaka, S., Shindo, T. \& Furukawa, T. (2007). Emotional distress and its correlates among parents of children with pervasive developmental disorders. Psychiatry and Clinical Neurosciences, 61(6), pp 651-657. 